Western University

Scholarship@Western

$8-2014$

\title{
Practice Patterns and Trends in the Use of Medical Therapy in Patients Undergoing Percutaneous Coronary Intervention in Ontario
}

Pallav Garg

Western University, PGARG3@UWO.CA

Harindra C. Wijeysundera

University of Toronto

Lingsong Yun

Institute for Clinical Evaluative Sciences

Warren J. Cantor

University of Toronto

Dennis T.Ko

University of Toronto

Follow this and additional works at: https://ir.lib.uwo.ca/medpub

Part of the Medicine and Health Sciences Commons

Citation of this paper:

Garg, Pallav; Wijeysundera, Harindra C.; Yun, Lingsong; Cantor, Warren J.; and Ko, Dennis T., "Practice Patterns and Trends in the Use of Medical Therapy in Patients Undergoing Percutaneous Coronary Intervention in Ontario" (2014). Department of Medicine Publications. 148.

https://ir.lib.uwo.ca/medpub/148 


\section{Practice Patterns and Trends in the Use of Medical Therapy in Patients Undergoing Percutaneous Coronary Intervention in Ontario}

Pallav Garg, MBBS, MSc, FRACP; Harindra C. Wijeysundera, MD, PhD, FRCPC; Lingsong Yun, MSc; Warren J. Cantor, MD, FRCPC; Dennis T. Ko, MD, MSc, FRCPC

Background-Clinical guidelines emphasize medical therapy as the initial approach to the management of patients with stable coronary artery disease (CAD). However, the extent to which medical therapy is applied before and after percutaneous coronary intervention $(\mathrm{PCl})$ in contemporary clinical practice is uncertain. We evaluated medication use for patients with stable $\mathrm{CAD}$ undergoing $\mathrm{PCl}$, and assessed whether the COURAGE study altered medication use in the Canadian healthcare system.

Methods and Results-A population-based cohort of 23680 older patients $>65$ years old) with stable CAD undergoing PCI in Ontario between 2003 and 2010 was assembled. Optimal medical therapy (OMT) was defined as prescription for a $\beta$-blocker, statin, and either angiotensin-converting enzyme inhibitor or angiotensin II receptor blocker in the 90 days before $\mathrm{PCl}$, and the same medications plus thienopyridine 90 days following $\mathrm{PCl}$. Prior to $\mathrm{PCl}, 8023$ (33.9\%) patients were receiving OMT, 11891 (50.2\%) were on suboptimal therapy, and 3766 (15.9\%) were not prescribed any medications of interest. There was significant improvement in medical therapy following PCI (OMT: 11 149 [47.1\%], suboptimal therapy: 11591 [48.9\%], and none: 940 [4.0\%], $P<0.001)$. Utilization rate of OMT reduced significantly after the publication of COURAGE (34.9\% before versus $32.8 \%$ after, $P<0.001)$. Similarly, the rate of OMT following $\mathrm{PCl}$ was lower in the period after publication of COURAGE (47.3\% before versus $46.9 \%$ after, $P<0.001)$.

Conclusions-OMT was prescribed in about 1 in 3 patients prior to $\mathrm{PCl}$ and less than half after $\mathrm{PCl}$. In contrast to the anticipated impact of COURAGE, we found lower rates of medication use in PCl patients after its publication. (J Am Heart Assoc. 2014;3: e000882 doi: 10.1161/JAHA.114.000882)

Key Words: optimal medical therapy • outcomes • percutaneous coronary intervention • stable coronary artery disease

\begin{abstract}
A dvances in medical therapy have significantly improved the prognosis of patients with stable coronary artery disease (CAD). ${ }^{1,2}$ The Clinical Outcomes Utilizing Revascularization and Aggressive Drug Evaluation (COURAGE) study is a landmark randomized trial comparing the effectiveness of optimal medical therapy versus percutaneous coronary intervention $(\mathrm{PCI})$ in patients with stable CAD. ${ }^{3}$ The study showed similar rates of cardiovascular events in the overall population
\end{abstract}

From the Department of Medicine, London Health Sciences Center, Western University, London, ON, Canada (P.G.); Institute for Clinical Evaluative Sciences, Toronto, ON, Canada (H.C.W., L.Y., D.T.K.); Sunnybrook Health Sciences Center, Toronto, ON, Canada (H.C.W., D.T.K.); Southlake Regional Health Center, Newmarket, ON, Canada (W.J.C.); Department of Medicine, University of Toronto, Toronto, ON, Canada (H.C.W., W.J.C., D.T.K.).

Correspondence to: Pallav Garg, MBBS, MSc, FRACP, Room C6-106, University Hospital, 339 Windermere Road, London, ON, Canada, N6A 5A5. Email: pgarg@post.harvard.edu

Received March 4, 2014; accepted May 24, 2014.

(c) 2014 The Authors. Published on behalf of the American Heart Association, Inc., by Wiley Blackwell. This is an open access article under the terms of the Creative Commons Attribution-NonCommercial License, which permits use, distribution and reproduction in any medium, provided the original work is properly cited and is not used for commercial purposes. and in the older patient population., ${ }^{3,4}$ These results are consistent with prior studies and meta-analyses comparing medical therapy and $\mathrm{PCl}$ for future adverse cardiac events. ${ }^{5-7}$ In addition, while the degree of angina relief was slightly higher in the $\mathrm{PCl}$ group, substantial improvement in angina was also seen in the medical therapy group. ${ }^{3}$ Accordingly, existing clinical practice guidelines reinforce medical therapy as the initial approach to the management of patients with stable angina, and reserve $\mathrm{PCl}$ for patients with persistent symptoms despite optimal medical therapy. ${ }^{8}$

Despite the widespread attention to the importance of medical therapy received in the medical literature and in the lay press, a study demonstrated that there was little change in medical therapy prior to and after $\mathrm{PCl}$ in the United States after publication of the COURAGE trial. ${ }^{9}$ There are many potential reasons why the COURAGE results may not have changed practice patterns, one of which could be due to the existing structure of the United States healthcare system, where substantial financial incentives exist to perform invasive cardiac procedures. ${ }^{10,11}$ The Canadian healthcare system, in contrast, has a single-payer model where incentives to perform procedures are less. As a result, it is 
well known that Canada has lower capacity to perform coronary invasive procedures in both acute and nonacute indications as compared to the United States. ${ }^{12-16}$ We theorized that physicians in Canada may be more inclined to translate current knowledge to optimize medical therapy prior to elective $\mathrm{PCl}$.

We therefore sought to evaluate the practice patterns and trends in the use of optimal medical therapy in patients with stable $\mathrm{CAD}$ undergoing $\mathrm{PCl}$ and whether the publication of COURAGE changed medical therapy practice patterns in the Canadian healthcare system.

\section{Methods}

The Cardiac Care Network of Ontario maintains a prospective clinical registry of all individuals who undergo $\mathrm{PCl}$ in Ontario, Canada. ${ }^{17}$ All hospitals performing $\mathrm{PCl}$ are required to collect information on patients' clinical characteristics, as well as procedural information on the number of stents, characteristics of each stent, and location of stent placement. We conducted a retrospective cohort study by linking this registry to several population-based administrative databases, namely, the Discharge Abstract Database of the Canadian Institute for Health Information (hospital admissions), the Ontario Health Insurance Plan database (physician service claims), the Registered Persons Database (vital statistics), the Ontario Drug Benefit database (prescriptions for individuals $>65$ years of age), and the Canadian census. ${ }^{18,19}$ These databases have been previously validated for many outcomes, exposures, and comorbidities. The linkages were performed using unique encrypted patient identifiers to protect patient confidentiality. The need for patient informed consent was waived under Ontario's health information privacy legislation.

\section{Study Sample}

Patients aged 66 years and over with stable CAD undergoing PCl from December 1, 2003 to March 31, 2010 in Ontario were included in the study. To define a cohort of stable CAD patients for elective procedures, those with myocardial infarction, revascularization with $\mathrm{PCl}$, or coronary artery bypass grafting surgery with or without valve surgery within 12 months of the index $\mathrm{PCl}$ were excluded. Patients admitted to the hospital with acute coronary syndromes were excluded. Patients with severe comorbidities (eg, metastatic cancer, or severe renal, liver, or pulmonary disease) within the past year were also excluded because of competing risk of death and reasons precluding optimal use of medications. Patients with potential complications for evidenced-based therapies, such as hyperkalemia or heart block were also excluded in order to accurately assess appropriate medication use. Comorbidities were identified using the Cardiac Care Network clinical registry, and information from the Canadian Institute for Health Information Discharge Abstract Database, which is based on International Classification of Diseases 10th Revision codes.

\section{Ascertainment of Medical Therapy Before and After $\mathrm{PCl}$}

The Ontario Drug Benefits database was used to ascertain medication use before and after the index $\mathrm{PCl}$ for patients over 65 years of age. We assessed the use of long-acting nitrates, $\beta$-blockers, calcium channel blockers, statins, angiotensin-converting enzyme (ACE)-inhibitors, and angiotensin receptor blockers (ARB) prior to $\mathrm{PCl}$ based on prescriptions within 90 days prior to and after index $\mathrm{PCI}$. In addition to those medications, thienopyridine (clopidogrel or ticlopidine) use was assessed in the 90 days following $\mathrm{PCl}$ (prasugrel and ticagrelor were unavailable during the study period). There is a very high (>99\%) agreement rate between the Ontario Drug Benefit prescription claims record and dispensed records from pharmacy. ${ }^{20}$ Aspirin use could not be formally evaluated because many patients purchase aspirin over the counter and this is not recorded in the Ontario Drug Benefits database.

\section{Definition of Optimal Medical Therapy}

We defined "optimal medical therapy" as prescription for $\beta$ blocker, statin, and either ACE-inhibitor or ARB in the 90 days prior to $\mathrm{PCl}$, and the same medications along with a thienopyridine in the 90 days following PCI. ACE-inhibitor or ARB use was considered in keeping with the COURAGE definition of optimal medical therapy where ACE-inhibitors or ARB were encouraged in all patients with stable CAD for secondary prevention. ${ }^{3}$ Suboptimal therapy was defined as prescription for at least 1 of the above medications. No medical therapy was defined as the absence of all of these medications. Recognizing that symptomatic anginal relief is important in patients with stable angina (particularly pre-PCI), we considered an alternate definition of medical therapy based on the prescription of any 2 medications from the following in the 90 days pre-PCl: $\beta$-blocker, long-acting nitrate, calcium channel blocker or either ACE-inhibitor or $\mathrm{ARB}$, and the same medications along with a thienopyridine and statin in the 90 days following PCl ("symptom-oriented medical therapy"). Secondary end points also included the prescription rates of individual medications.

\section{Statistical Analysis}

We compared demographic characteristics, clinical characteristics, stratified by (1) medication use, and (2) COURAGE 
publication using $\chi^{2}$ tests for categorical variables and $t$ tests for continuous variables. We used the period December 1, 2003 to March 31, 2007 for "pre-COURAGE" and July 1, 2007 to March 31, 2010 for the "post-COURAGE" period, allowing for a 3-month period for the dissemination of the trial results (COURAGE was published on March 26, 2007).

Medication prescription rates before and after $\mathrm{PCl}$ were compared in the overall cohort as well as in the periods before and after the publication of the COURAGE trial to examine whether the use of medical therapy changed after the publication of the COURAGE trial. Continuous variables are reported as mean $\pm S D$ and compared using $t$ tests for normally distributed data. Categorical variables are reported as percentages and compared using the $\chi^{2}$ test. The McNemar test was used to compare medical therapy use before and after the publication of the COURAGE trial.

We also used a logistic regression model to examine predictors of optimal medical therapy in the 90 days prior to the $\mathrm{PCl}$. Variables considered and entered in the regression model included demographic and clinical variables such as age, sex, Canadian Cardiovascular Society angina class, prior cardiovascular disease and other comorbidities, hospital status, and procedure year. It was possible for some patients to have been referred for cardiac catheterization by primary care physicians or other physicians directly, without prior evaluation by a cardiologist or an internist on an outpatient basis, and vice versa. Thus, we included outpatient physician (primary care physician and/or cardiologist or internist) visits within the preceding 90 days in the model. PCl during the same session as the cardiac catheterization (commonly referred to as ad-hoc PCl) was not considered in this model because it does not impact on medical treatment prior to $\mathrm{PCl}$.

All statistical tests are 2 -sided and a $P$-value $<0.01$ was considered statistically significant. All analyses were performed using SAS 9.2 (SAS Institute, Cary, NC).

\section{Results}

The initial registry population in the study period included $122528 \mathrm{PCl}$ procedures. After excluding patients who were younger than 65 years old (68 591 patients), patients with myocardial infarction in the past year (19 216 patients), $\mathrm{PCl}$ or coronary artery bypass grafting surgery in the past year (6014 patients), patients with severe comorbidities or potential contraindications to medical therapy (1775 patients), and missing data, the final study population included 23680 patients with stable CAD who received PCl from December 1, 2003 to March 31, 2010 (Figure).

\section{Baseline Characteristics According to Medical Therapy Prior to PCI}

The mean age of the cohort was 74.1 years and the majority (64\%) were male (Table 1). Of the 23680 patients undergoing $\mathrm{PCl}$, only 8023 patients (33.9\%) were on optimal medical therapy, 11891 (50.2\%) were receiving suboptimal medical therapy, and $15.9 \%$ were not on any $\beta$-blocker, statin, or either ACE-inhibitor or ARB in the 90 days before the procedure. In general, patients who were receiving optimal medical therapy before their $\mathrm{PCl}$ had higher rates of comorbidities, prior cardiovascular disease, and to have undergone a prior stress test compared to patients who received suboptimal or no medical therapy prior to $\mathrm{PCl}$, and were less likely to have moderate to severe angina (Table 1). In addition, patients on optimal medical therapy were more often evaluated by a primary care physician and/or cardiologist or an internist in an outpatient setting in the 90 days prior to $\mathrm{PCl}$. For example, $86.1 \%$ of patients receiving optimal medical therapy were evaluated by a cardiologist or an internist in the 90 days prior to $\mathrm{PCl}$, compared with $69.6 \%$ in the suboptimal medical therapy group, and $27.3 \%$ in the no medical therapy group. Performance of ad-hoc PCl was common (14 045 patients, 59.3\%), and most commonly observed among patients not on any medical therapy prior to $\mathrm{PCl}(85.2 \%)$ as compared to those on optimal medical therapy (46.2\%) (Table 1).

\section{Factors Associated With Optimal Medical Therapy Prior to $\mathrm{PCl}$}

In the multivariate analysis, younger age, lower income, remote history of revascularization, performance of stress test prior to $\mathrm{PCl}$, and cardiac risk factors or conditions were associated with significantly increased likelihood of being on optimal medical therapy (Table 2). Cardiologist assessment was associated with a 2-fold increased likelihood of being on optimal medical therapy (odds ratio $2.31 ; 95 \% \mathrm{Cl} 2.12$ to 2.51). Patients at lower angina classification were more likely to receive optimal therapy than patients with Canadian Cardiovascular Society class 4 angina. There was no evidence of increased use of optimal medical therapy over time. In fact, patients who received $\mathrm{PCl}$ in 2003-2005 (odds ratio 1.76; $95 \% \mathrm{Cl} 1.58$ to 1.96 ) and 2005-2006 (odds ratio 1.6; $95 \% \mathrm{Cl}$ 1.44 to 1.79 ) had significantly higher likelihood of receiving optimal medical therapy compared with patients undergoing $\mathrm{PCl}$ in 2009-2010 (Table 2).

\section{Medical Therapy Before and After PCl}

Medication prescription rates improved following $\mathrm{PCl}$, with 8023 patients $(33.9 \%, 95 \% \mathrm{Cl}, 33.3$ to 34.5$)$ receiving optimal 


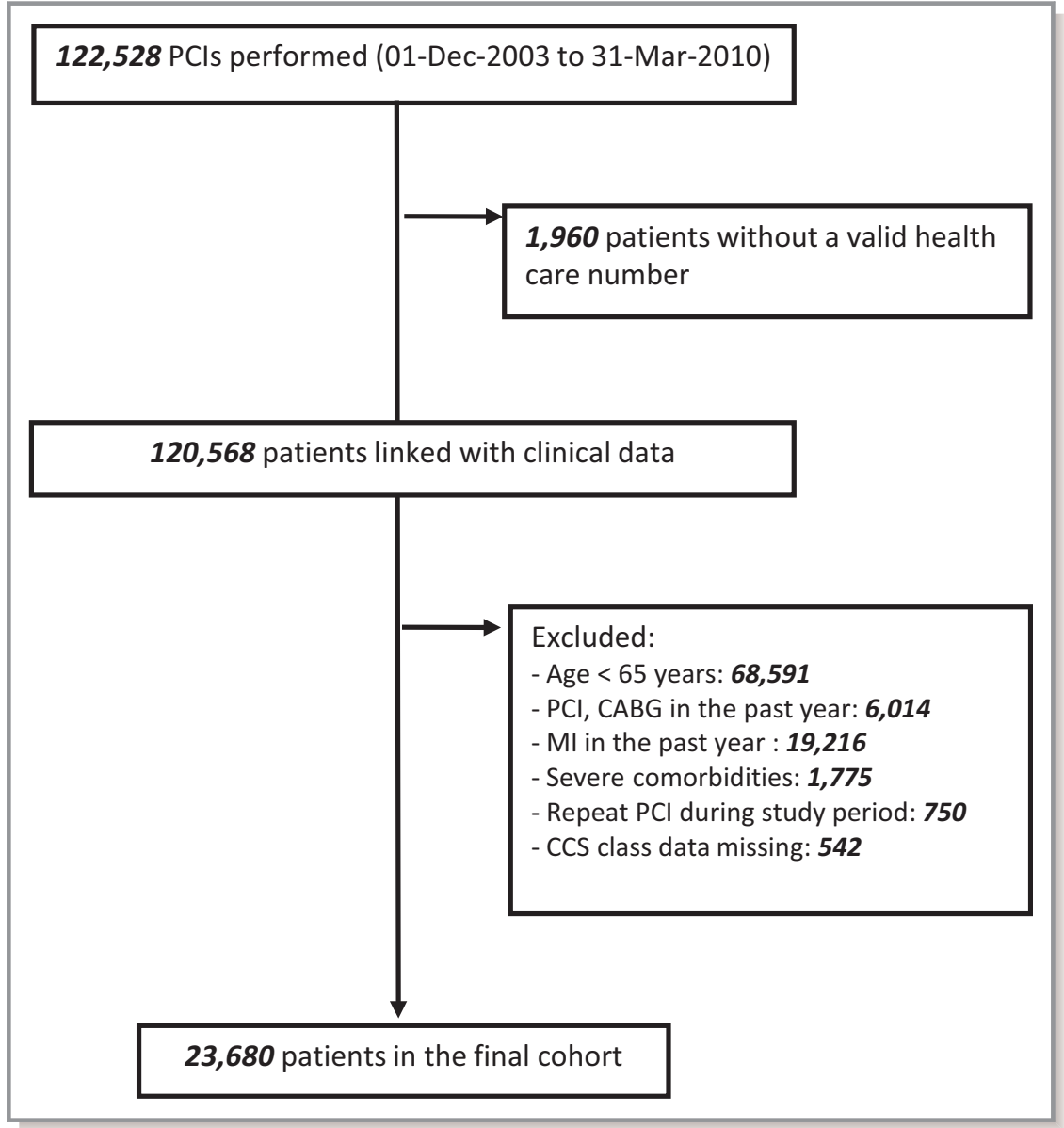

Figure. Cohort details. CABG indicates coronary artery bypass graft surgery; CCS, Canadian Cardiovascular Society; MI, myocardial infarction; PCI, percutaneous coronary intervention.

medical therapy in the 90 days prior and 11153 patients (47.1\%, $95 \% \mathrm{Cl} 46.5$ to 47.7$)$ receiving optimal medical therapy in the 90 days post-PCI (Table 3). Prescription rates of $\beta$-blockers increased significantly from $56.9 \%$ before $\mathrm{PCI}$ to $70.6 \%$ after $\mathrm{PCl}(P<0.001)$. Similarly, prescription rates of statins $(64.3 \%$ to $84.6 \%)$, ACE inhibitors or ARBs $162.3 \%$ to $74.5 \%)$, and clopidogrel $(22.7 \%$ to $87.1 \%)$ increased significantly after $\mathrm{PCl}$, whereas the use of long-acting nitrates (23.5\% to $14.5 \%)$ and calcium-channel blockers decreased (38.8\% to $30.9 \%$ ), as might be expected following revascularization (Table 3).

\section{Medical Therapy Before and After COURAGE}

A comparable number of patients underwent $\mathrm{PCl}$ in the period before (11984 patients) and after (11 696 patients) publication of the COURAGE trial. Although patients were largely similar in terms of their demographic and clinical characteristics (Table 4), the rate of optimal medical therapy prior to $\mathrm{PCl}$ reduced slightly following COURAGE $(32.8 \%, 95 \%$
$\mathrm{Cl} 34.1$ to 35.8 after versus $34.9 \%, 95 \% \mathrm{Cl} 34.1$ to 35.8 before, $P<0.001$; Table 5). The rates of the individual medications prescribed before $\mathrm{PCl}$ were also lower or unchanged during the post-COURAGE period. Less than two thirds of the patients were on symptom-oriented medical therapy prior to $\mathrm{PCl}$, and rates were lower in the postCOURAGE period (Table 5).

Similarly, the rate of optimal medical therapy following $\mathrm{PCl}$ was lower in the period after the COURAGE trial compared with before the trial $(47.3 \%, 95 \% \mathrm{Cl} 46.4$ to 48.2 before versus $46.9 \%, 95 \% \mathrm{Cl} 46.0$ to 47.8 after, $P<0.001$; Table 4). Rates of the individual medications prescribed after $\mathrm{PCl}$ were also lower or unchanged during the post-COURAGE period. Similarly, the rate of symptom-oriented medical therapy following $\mathrm{PCl}$ was unchanged in the post-COURAGE period (Table 6). There was no significant change in medication prescription rates after the COURAGE trial publication before or after $\mathrm{PCl}$ when stratified by severity of angina based on Canadian Cardiovascular Society class (Table 7). 
Table 1. Demographic and Clinical Characteristics, Stratified by Medical Therapy 90 Days Prior to PCI

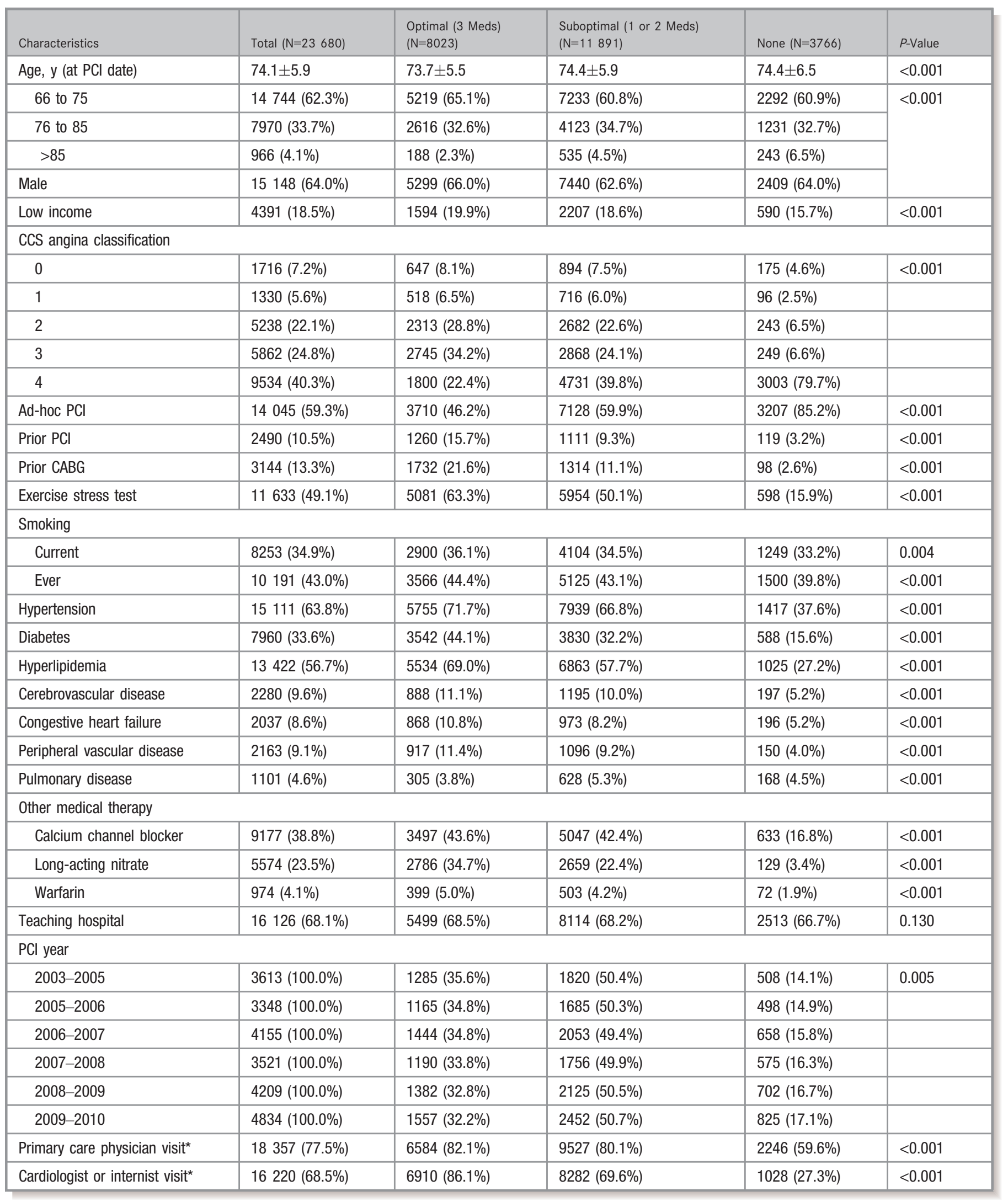

CABG indicates coronary artery bypass graft surgery; CCS, Canadian Cardiovascular Society; PCl, percutaneous coronary intervention. * In the 90 days before $\mathrm{PCl}$. 
Table 2. Factors Associated With Optimal Medical Therapy Prior to $\mathrm{PCl}^{*}$

\begin{tabular}{|c|c|c|}
\hline Variables & Odds Ratio $(95 \% \mathrm{Cl}$ ) & $P$-Value \\
\hline Age, y (reference $>85$ years) & & $<0.001$ \\
\hline 66 to 75 & 1.37 (1.15 to 1.64$)$ & \\
\hline 76 to 85 & 1.31 (1.1 to 1.57$)$ & \\
\hline Male & 1.07 (1.0 to 1.14$)$ & 0.042 \\
\hline Low income & 1.15 (1.06 to 1.24$)$ & $<0.001$ \\
\hline $\begin{array}{l}\text { CCS angina classification } \\
\text { (reference CCS 4) }\end{array}$ & & $<0.001$ \\
\hline 0 to 1 & 1.6 (1.44 to 1.78$)$ & \\
\hline 2 & 1.89 (1.72 to 2.08$)$ & \\
\hline 3 & 2.03 (1.86 to 2.23 ) & \\
\hline Prior PCl & 1.79 (1.63 to 1.97$)$ & $<0.001$ \\
\hline Prior CABG & 2.04 (1.89 to 2.22) & $<0.001$ \\
\hline Exercise stress test & 1.35 (1.26 to 1.45$)$ & $<0.001$ \\
\hline Current smoking & $1.0(0.93$ to 1.06$)$ & 0.930 \\
\hline Hypertension & 1.46 (1.36 to 1.57$)$ & $<0.001$ \\
\hline Diabetes & 1.62 (1.52 to 1.72$)$ & $<0.001$ \\
\hline Hyperlipidemia & 1.64 (1.53 to 1.77$)$ & $<0.001$ \\
\hline Cerebrovascular disease & 1.1 (1.0 to 1.22$)$ & 0.055 \\
\hline Congestive heart failure & 1.57 (1.41 to 1.74$)$ & $<0.001$ \\
\hline Peripheral vascular disease & 1.15 (1.04 to 1.27$)$ & 0.007 \\
\hline Pulmonary disease & $0.63(0.55$ to 0.73$)$ & $<0.001$ \\
\hline Teaching hospital & 0.98 (0.92 to 1.05$)$ & 0.620 \\
\hline $\begin{array}{l}\text { PCl year } \\
\text { (2009-2010 as reference) }\end{array}$ & & $<0.001$ \\
\hline 2003-2005 & 1.76 (1.58 to 1.96$)$ & \\
\hline 2005-2006 & 1.6 (1.44 to 1.79$)$ & \\
\hline $2006-2007$ & $1.2(1.06$ to 1.29$)$ & \\
\hline 2007-2008 & 1.15 (1.04 to 1.28$)$ & \\
\hline 2008-2009 & 1.06 (1.05 to 1.21$)$ & \\
\hline Primary care physician visit & 1.13 (1.05 to 1.21$)$ & 0.002 \\
\hline Cardiologist or internist visit & 2.2 (2.02 to 2.41$)$ & $<0.001$ \\
\hline
\end{tabular}

CABG indicates coronary artery bypass graft surgery; CCS, Canadian Cardiovascular Society; PCl, percutaneous coronary intervention.

*The model predicts the use of optimal medical therapy 90 days prior to $\mathrm{PCI}$. The adjusted odds ratios were derived from multivariate logistic regression model. This model had a c-index (area under the receiving operating curve) of 0.74 .

\section{Discussion}

Our study provides new insights into the practice pattern of medical therapy in patients with stable angina undergoing revascularization with $\mathrm{PCl}$ in Canada. Our results demonstrate that only one third of patients undergoing $\mathrm{PCl}$ for stable coronary artery disease were prescribed optimal medical therapy with $\beta$-blockers, statins, and either ACE-inhibitors or
ARBs in the 90 days prior to their procedure. While medication prescription rates improved following $\mathrm{PCl}$, less than half of patients were receiving optimal medical therapy in the 90 days following $\mathrm{PCl}$. In addition, there was no substantial change in this practice pattern over the study period, including following the publication and dissemination of the COURAGE trial in 2007. These findings suggest that despite mounting evidence of the importance of medical therapy in patients with stable coronary disease, and the strong clinical guideline recommendations for maximizing the medical therapy prior to and in conjunction with revascularization, ${ }^{8}$ most patients are still treated with inadequate medical therapy. We also found relatively low rates of use of anti-anginals such as nitrates prior to $\mathrm{PCl}$ even in patients with significant symptoms.

The concept of applying optimal medical therapy was endorsed in the COURAGE trial, in which $\approx 90 \%$ of the medically treated cohort was compliant with aspirin, statin, and $\beta$-blocker therapies at 1 year. ${ }^{3}$ At 3 years, $75 \%$ of patients were on ACE inhibitors or ARBs, $92 \%$ were on a statin, and $86 \%$ were on a $\beta$-blocker in the medical therapy arm and similar compliance was present even in the $\mathrm{PCl}$ group. This is in contrast to "real world" practice, both in terms of prescription and compliance with recommended antianginal and preventative medical therapy. Our results are in keeping with prior large studies that have shown much lower rates of medical therapy in patients with coronary artery disease. ${ }^{9,21-23}$ Borden et al showed that among patients with stable CAD undergoing PCI in the United States, less than half received optimal medical therapy prior to $\mathrm{PCl}$ and approximately two thirds of patients received it after discharge from the hospital following $\mathrm{PCl}$, with little change after the publication of the COURAGE trial. $^{9}$

We initially hypothesized that physicians may be more inclined to apply COURAGE results in the Canadian healthcare system, where there is a government-regulated single-payer model with perhaps less incentive to perform procedures and where waiting lists are traditionally longer. ${ }^{10,15}$ In addition, under the Ontario Drug Benefit Program, medications are generally available with low co-payment and dispensing fees. This was expected to result in better medication prescription and adherence compared with other jurisdictions with limited medication coverage and higher co-payments. However, we found that the prescription rates of optimal medical therapy were lower in our study compared with the US study. In addition, a surprising $16 \%$ of the patients undergoing $\mathrm{PCl}$ had not received any cardiac medications we assessed prior to the $\mathrm{PCl}$ procedure.

We also found that patients with angina at higher Canadian Cardiovascular Society class were less likely to be on medical therapy prior to $\mathrm{PCl}$. The reasons for this finding are not entirely clear, although it is possible that these patients had 
Table 3. Medication Prescription Rates Before and After PCl

\begin{tabular}{|l|l|l|l|}
\hline \multirow{2}{*}{ Medication } & \multicolumn{2}{|l|}{ No. (\%), (95\% Cl) of Patients } & \multirow{2}{*}{ P-Value } \\
\cline { 2 - 4 } & Pre-PCl $(90$ Days) & Post-PCl (90 Days) & $<0.001$ \\
\hline Optimal medical therapy & $33.9(33.3$ to 34.5$)$ & $47.1(46.5$ to 47.7$)$ & 0.001 \\
\hline Suboptimal medical therapy & $50.2(49.6$ to 50.9$)$ & $48.9(48.3$ to 49.6$)$ & $<0.001$ \\
\hline None & $15.9(15.4$ to 16.4$)$ & $4.0(3.7$ to 4.2$)$ & $<0.001$ \\
\hline Individual medications & $23.5(23.0$ to 24.1$)$ & $14.5(14.0$ to 14.9$)$ & $<0.001$ \\
\hline Long-acting nitrate & $56.9(56.2$ to 57.5$)$ & $70.6(70.1$ to 71.2$)$ & $<0.001$ \\
\hline B-Blocker & $38.8(38.1$ to 39.4$)$ & $30.9(30.3$ to 31.5$)$ & $<0.001$ \\
\hline Calcium channel blocker & $64.3(63.6$ to 64.9$)$ & $84.6(84.1$ to 85.0$)$ & $<0.001$ \\
\hline Statin & $62.3(61.7$ to 63.0$)$ & $74.5(73.9$ to 75.0$)$ & $<0.001$ \\
\hline ACE-l/ARB & $22.7(22.1$ to 23.2$)$ & $87.1(86.7$ to 87.5$)$ & $<0.001$ \\
\hline Clopidogrel & $61.2(60.6$ to 61.8$)$ & $57.9(57.3$ to 58.5$)$ & \\
\hline Symptom-oriented medical therapy & \multicolumn{2}{|l|}{} \\
\hline
\end{tabular}

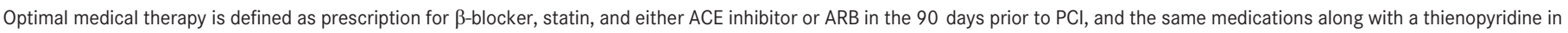

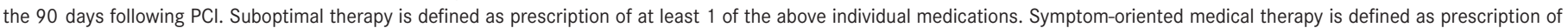

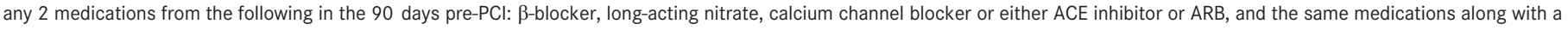
thienopyridine and statin in the 90 days following PCI. ACE indicates angiotensin-converting enzyme; ARB, angiotensin receptor blocker; PCI, percutaneous coronary intervention.

more symptoms given the lack of appropriate medical therapy prior to PCl. An alternative explanation may be that physicians want to refer these patients for more urgent catheterization and $\mathrm{PCl}$, given the severity of their symptoms even before instituting appropriate medical therapy, although there is little justification for such an approach.

There are several possible reasons why medical therapy is underprescribed in patients with stable CAD and why the COURAGE trial results have not been implemented in common clinical practice. First, it has been shown that patients overestimate the benefits of $\mathrm{PCl}$ by believing that $\mathrm{PCl}$ would prevent myocardial infarction or fatality. ${ }^{24}$ Such belief may lead to a desire of a "quick-fix" for their symptoms rather than to comply with a daily medication regimen for a long period of time. Second, physicians may not universally accept the results of recent trials, such as COURAGE, or there may be a knowledge gap regarding appropriate management of patients with stable $\mathrm{CAD}$, believing that $\mathrm{PCl}$ is better compared to medical therapy. ${ }^{25}$ For example, a recent study indicates that about $20 \%$ of cardiologists still believe that the PCI may reduce death or prevent myocardial infarction in stable CAD patients. ${ }^{24}$ Third, we found that many patients who were on suboptimal or no therapy received $\mathrm{PCl}$ as an ad-hoc procedure. The reasons for such high rates of ad-hoc $\mathrm{PCl}$ are likely multifactorial. From the patient's perspective, combining the diagnostic angiogram and the intervention in a single setting is convenient, and this approach forms part of both patients' and physicians' expectations. It is also possible that physicians and patients may be more inclined to undertake ad-hoc $\mathrm{PCl}$ rather than prescribe medical therapy and delay any revascularization, given the severity of their patients' symptoms. Nevertheless, while ad-hoc PCl may be more acceptable in the acute coronary syndrome setting where $\mathrm{PCl}$ improves outcomes, delayed or non-ad-hoc PCl may be preferable in patients with stable angina. ${ }^{26}$ This allows for a proper and frank discussion of all therapeutic options in a more relaxed setting, including optimization or intensification of medical therapy.

Our study adds to the growing literature indicating suboptimal use of proven therapies in practice and has important implications for the contemporary management of patients with stable CAD. Current practice guidelines recommend optimizing medical therapy for improvement of symptoms and prognosis prior to consideration of revascularization. Improved utilization of medications is a significant opportunity for improvement in health care of patients with cardiovascular disease. Revascularization may be safely deferred or may not be required in patients appropriately treated with medical therapy, thereby reducing societal costs at the same time as improving survival. Our study reinforces the importance of appropriateness criteria for coronary revascularization. Indeed, policy makers and insurers may eventually mandate the need for appropriate and aggressive medical therapy before reimbursing $\mathrm{PCl}$ procedures.

Our study has several important limitations. First, we did not assess prescription of aspirin because we were unable to capture this medication in the Ontario Drug Benefits database because many patients purchase aspirin over the counter rather than through the drug benefit program. Second, our study was limited to an older cohort $>65$ years 
Table 4. Demographic and Clinical Characteristics Before and After Publication of COURAGE

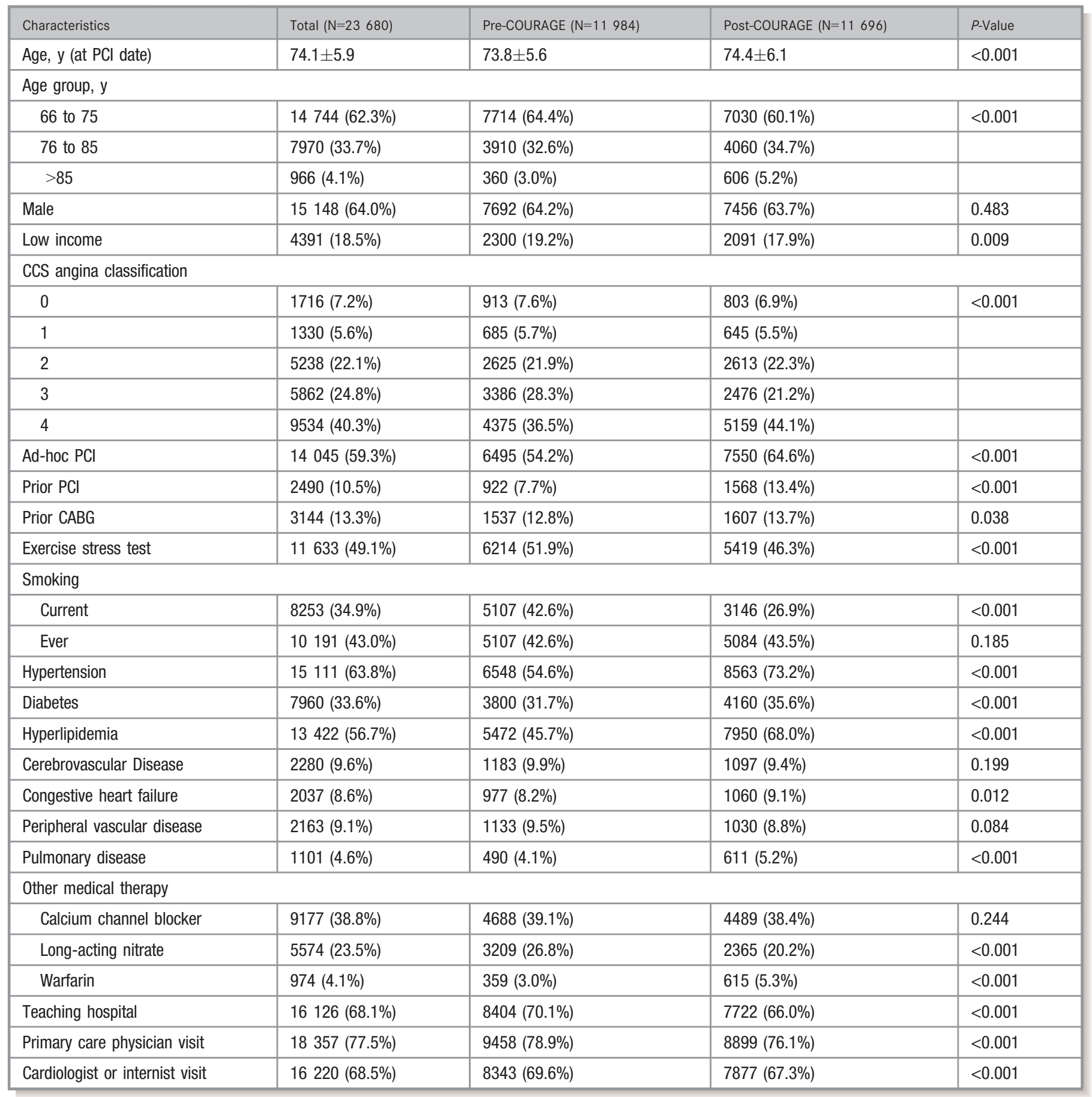

CABG indicates coronary artery bypass graft surgery; CCS, Canadian Cardiovascular Society; COURAGE, Clinical Outcomes Utilizing Revascularization and Aggressive Drug Evaluation; $\mathrm{PCl}$, percutaneous coronary intervention.

of age) because we did not have information on prescriptions for younger patients. However, the elderly population represents a high-risk group with higher baseline cardiovascular risk profile and derives equal if not more benefit from medical therapy as younger patients. Third, medication prescription was used as a surrogate for medication use and compliance, and we were unable to determine whether patients actually took their medication once it was dispensed. However, this misclassification bias would tend to overestimate medication use. Fourth, we were unable to control for all factors that might influence a physician's decision to prescribe (or not prescribe) medications, or fully define contraindications to therapy with these medications, which could underestimate optimal medical therapy use. 
Table 5. Medication Prescription Rates Before and After Publication of COURAGE in the 90 Days Prior to PCI

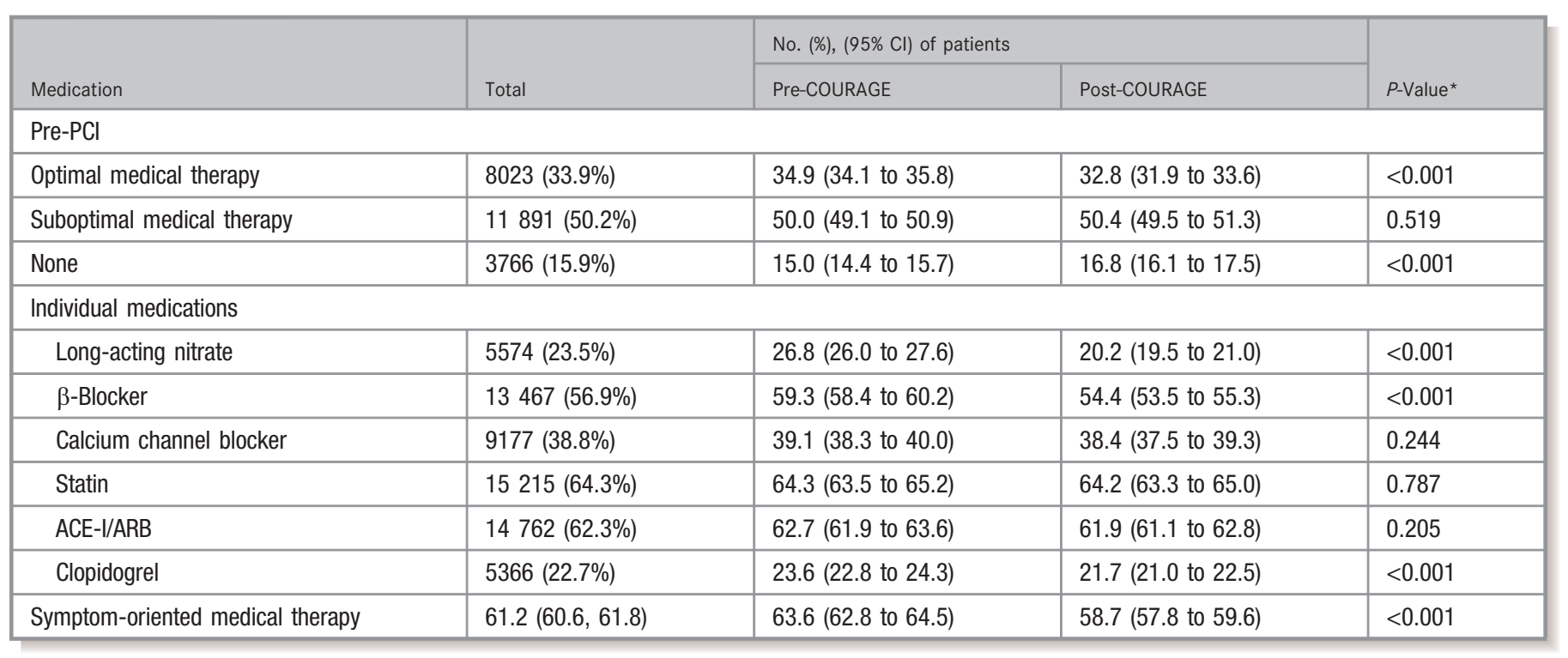

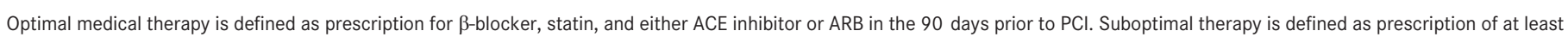

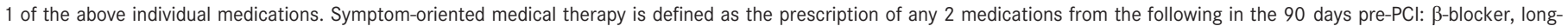

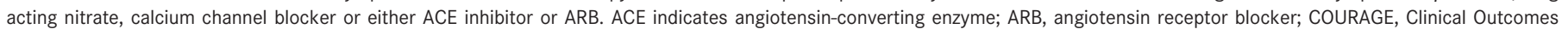
Utilizing Revascularization and Aggressive Drug Evaluation; PCI, percutaneous coronary intervention.

*McNemar test.

While it is possible that we have not captured all contraindications to therapy, this is unlikely to be different in the period before or after the COURAGE trial, thus not altering the finding that optimal medical therapy use did not differ after COURAGE. Finally, our data are from Ontario and may not reflect prescribing practices from other areas. However, Ontario is the largest province and encompasses a third of the Canadian population.

In conclusion, we found that among patients with stable CAD undergoing PCl, only a third of patients were prescribed

Table 6. Medication Prescription Rates Before and After Publication of COURAGE in the 90 Days After PCl

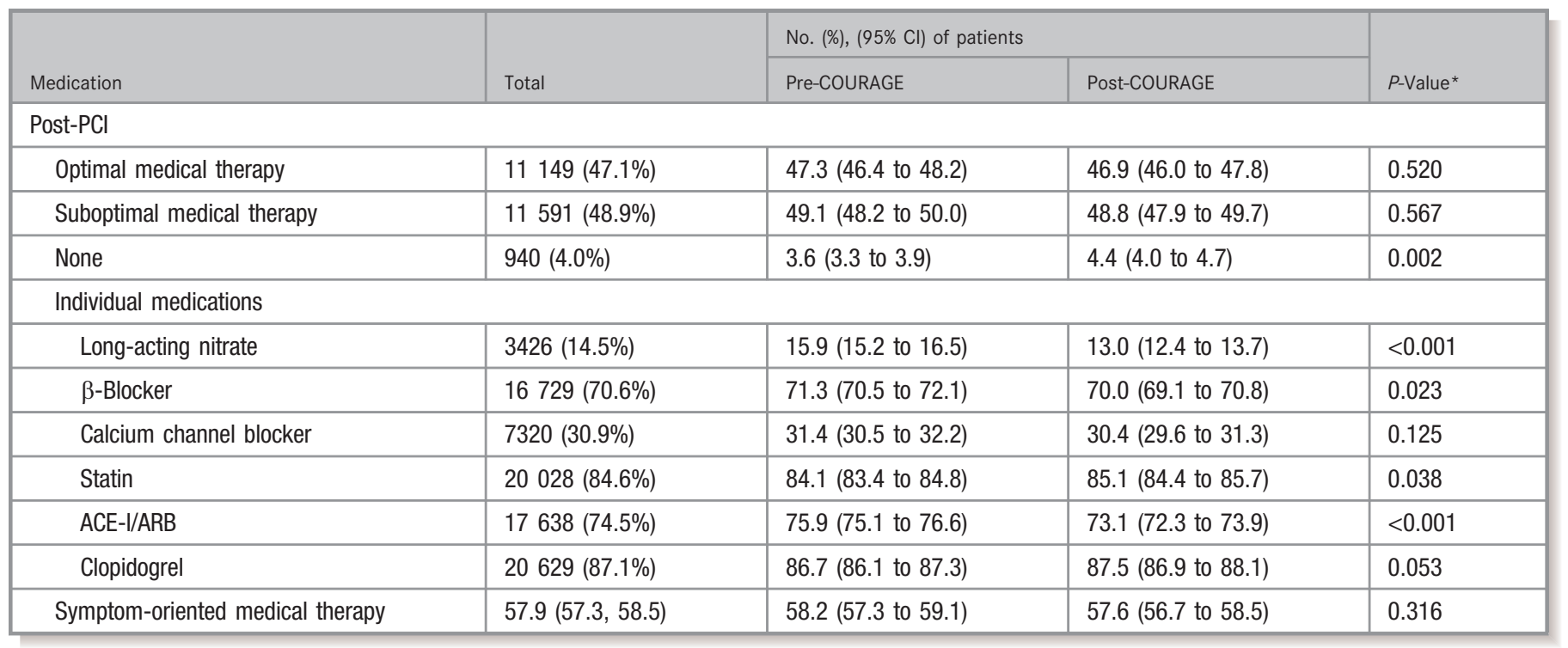

Optimal medical therapy is defined as prescription for $\beta$-blocker, statin, and either ACE inhibitor or ARB along with a thienopyridine in the 90 days following PCI. Suboptimal therapy is defined as prescription of at least 1 of the above individual medications. Symptom-oriented medical therapy is defined as the prescription of any 2 medications from the following: $\beta$-blocker, long-acting nitrate, calcium channel blocker or either ACE inhibitor or ARB, along with a thienopyridine and statin in the 90 days following PCl. ACE-I indicates angiotensinconverting enzyme inhibitor; ARB, angiotensin receptor blocker; COURAGE, Clinical Outcomes Utilizing Revascularization and Aggressive Drug Evaluation; PCI, percutaneous coronary intervention.

*McNemar test. 
Table 7. Medication Prescription Rates Before and After Publication of COURAGE, Stratified by Before and After PCl and CCS Class

\begin{tabular}{|c|c|c|c|}
\hline Medication & \multicolumn{2}{|c|}{ No. $(\%),(95 \% \mathrm{Cl})$ of Patients } & $P$-Value* \\
\hline \multicolumn{4}{|l|}{ CCS class 0 to $2(\mathrm{~N}=8284)$} \\
\hline Optimal medical therapy & $1775(42.0 \%)$ & $1703(41.9 \%)$ & 0.929 \\
\hline Suboptimal medical therapy & $2151(50.9 \%)$ & $2141(52.7 \%)$ & 0.104 \\
\hline Nitrate & $1042(24.7 \%)$ & $875(21.5 \%)$ & $<0.001$ \\
\hline$\beta$-Blocker & $2857(67.7 \%)$ & $2726(67.1 \%)$ & 0.609 \\
\hline Calcium channel blocker & $1629(38.6 \%)$ & $1659(40.9 \%)$ & 0.034 \\
\hline Statin & $3165(74.9 \%)$ & $3209(79.0 \%)$ & $<0.001$ \\
\hline Optimal medical therapy & $1728(40.9 \%)$ & $1560(38.4 \%)$ & 0.020 \\
\hline Suboptimal medical therapy & $2440(57.8 \%)$ & $2455(60.5 \%)$ & 0.013 \\
\hline None & $55(1.3 \%)$ & $46(1.1 \%)$ & 0.482 \\
\hline Nitrate & $532(12.6 \%)$ & $487(12.0 \%)$ & 0.402 \\
\hline$\beta$-Blocker & $2823(66.8 \%)$ & $2583(63.6 \%)$ & 0.002 \\
\hline Calcium channel blocker & $1400(33.2 \%)$ & $1484(36.5 \%)$ & 0.001 \\
\hline Statin & $3515(83.2 \%)$ & $3469(85.4 \%)$ & 0.006 \\
\hline ACE-I/ARB & $3132(74.2 \%)$ & $2863(70.5 \%)$ & $<0.001$ \\
\hline Nitrate & $2167(27.9 \%)$ & $1490(19.5 \%)$ & $<0.001$ \\
\hline$\beta$-Blocker & $4249(54.7 \%)$ & 3635 (47.6\%) & $<0.001$ \\
\hline Calcium channel blocker & $3059(39.4 \%)$ & $2830(37.1 \%)$ & 0.003 \\
\hline Statin & $4545(58.6 \%)$ & $4296(56.3 \%)$ & 0.004 \\
\hline ACE-I/ARB & $4561(58.8 \%)$ & $4396(57.6 \%)$ & 0.134 \\
\hline Clopidogrel & $1486(19.1 \%)$ & $1194(15.6 \%)$ & $<0.001$ \\
\hline \multicolumn{4}{|l|}{ Post-PCl } \\
\hline Optimal medical therapy & $3939(50.8 \%)$ & 3922 (51.4\%) & 0.445 \\
\hline Suboptimal medical therapy & $3448(44.4 \%)$ & $3248(42.5 \%)$ & 0.018 \\
\hline None & $374(4.8 \%)$ & $465(6.1 \%)$ & $<0.001$ \\
\hline Nitrate & $1369(17.6 \%)$ & $1038(13.6 \%)$ & $<0.001$ \\
\hline$\beta$-Blocker & $5723(73.7 \%)$ & $5600(73.3 \%)$ & 0.579 \\
\hline Calcium channel blocker & $2359(30.4 \%)$ & 2077 (27.2\%) & $<0.001$ \\
\hline Statin & $6563(84.6 \%)$ & $6481(84.9 \%)$ & 0.579 \\
\hline
\end{tabular}


Table 7. Continued

\begin{tabular}{|c|l|l|l|}
\hline \multirow{2}{*}{ Medication } & No. $(\%),(95 \% \mathrm{Cl})$ of Patients & \multirow{2}{*}{ P-Value } \\
\cline { 2 - 4 } & Pre-COURAGE & Post-COURAGE & $<0.001$ \\
\hline ACE-I/ARB & $5961(76.8 \%)$ & $5682(74.4 \%)$ & 0.488 \\
\hline Clopidogrel & $6640(85.6 \%)$ & $6562(85.9 \%)$ & \\
\hline
\end{tabular}

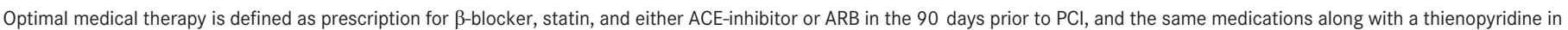
the 90 days following PCl. Suboptimal therapy is defined as prescription of at least 1 of the above individual medications.

ACE-I indicates angiotensin-converting enzyme inhibitor; ARB, angiotensin receptor blocker; CCS, Canadian Cardiovascular Society; COURAGE, Clinical Outcomes Utilizing

Revascularization and Aggressive Drug Evaluation; $\mathrm{PCl}$, percutaneous coronary intervention.

${ }^{\star}$ McNemar test.

optimal medical therapy in the 90 days prior to their procedure, and less than half were receiving optimal medical therapy in the 90 days following PCl. There was no substantial change in medical therapy prescription practice pattern over the study period, including following the publication of the COURAGE trial.

\section{Sources of Funding}

This study was funded by an operating grant from the Canadian Institute of Health Research (CIHR) operating grant MOP (102487). Dr Wijeysundera is supported by a Distinguished Clinical Scientist Award from the Heart and Stroke Foundation of Canada. Dr Ko is supported by a Clinician Scientist Award from the Heart and Stroke Foundation, Ontario Provincial Office. This study was supported by the Institute for Clinical Evaluative Sciences (ICES), which is funded by an annual grant from the Ontario Ministry of Health and Long-Term Care (MOHLTC). The authors acknowledge that the clinical registry data used in this publication are from the Cardiac Care Network of Ontario and its member hospitals. The Cardiac Care Network of Ontario serves as a system support to the MOHLTC, Local Health Integration Networks and service providers, and is dedicated to improving the quality, efficiency, access, and equity in the delivery of the continuum of adult cardiovascular services in Ontario, Canada. The Cardiac Care Network of Ontario is funded by the MOHLTC.

\section{Disclosures}

There are no financial relationships with any organizations that might have an interest in the submitted work, and no other relationships or activities that could appear to have influenced the submitted work. None of the listed organizations endorse this study nor do they have any influence on its publication.

\section{References}

1. Ford ES, Ajani UA, Croft JB, Critchley JA, Labarthe DR, Kottke TE, Giles WH, Capewell S. Explaining the decrease in U.S. deaths from coronary disease, 1980-2000. N Engl J Med. 2007;356:2388-2398.
2. Wijeysundera HC, Machado M, Farahati F, Wang X, Witteman W, van der Velde G, Tu JV, Lee DS, Goodman SG, Petrella R, O’Flaherty M, Krahn M, Capewell S. Association of temporal trends in risk factors and treatment uptake with coronary heart disease mortality, 1994-2005. JAMA. 2010;303:1841-1847.

3. Boden WE, O'Rourke RA, Teo KK, Hartigan PM, Maron DJ, Kostuk WJ, Knudtson M, Dada M, Casperson P, Harris CL, Chaitman BR, Shaw L, Gosselin G, Nawaz S, Title LM, Gau G, Blaustein AS, Booth DC, Bates ER, Spertus JA, Berman DS, Mancini GB, Weintraub WS. Optimal medical therapy with or without PCl for stable coronary disease. N Engl J Med. 2007;356:1503-1516.

4. Teo KK, Sedlis SP, Boden WE, O’Rourke RA, Maron DJ, Hartigan PM, Dada M, Gupta V, Spertus JA, Kostuk WJ, Berman DS, Shaw LJ, Chaitman BR, Mancini GB, Weintraub WS. Optimal medical therapy with or without percutaneous coronary intervention in older patients with stable coronary disease: a prespecified subset analysis of the COURAGE (clinical outcomes utilizing revascularization and aggressive drug evaluation) trial. J Am Coll Cardiol. 2009;54:1303-1308.

5. Dagenais GR, Lu J, Faxon DP, Kent K, Lago RM, Lezama C, Hueb W, Weiss M, Slater J, Frye RL. Effects of optimal medical treatment with or without coronary revascularization on angina and subsequent revascularizations in patients with type 2 diabetes mellitus and stable ischemic heart disease. Circulation. 2011;123:1492-1500.

6. Wijeysundera HC, Nallamothu BK, Krumholz HM, Tu JV, Ko DT. Meta-analysis: effects of percutaneous coronary intervention versus medical therapy on angina relief. Ann Intern Med. 2010;152:370-379.

7. Wijeysundera HC, Ko DT. Does percutaneous coronary intervention reduce mortality in patients with stable chronic angina: are we talking about apples and oranges? Circ Cardiovasc Qual Outcomes. 2009;2:123-126.

8. Fihn SD, Gardin JM, Abrams J, Berra K, Blankenship JC, Dallas AP, Douglas PS, Foody JM, Gerber TC, Hinderliter AL, King SB III, Kligfield PD, Krumholz HM, Kwong RY, Lim MJ, Linderbaum JA, Mack MJ, Munger MA, Prager RL, Sabik JF, Shaw LJ, Sikkema JD, Smith CR, Jr, Smith SC, Jr, Spertus JA, Williams SV. 2012 ACCF/AHA/ACP/AATS/PCNA/SCAI/STS guideline for the diagnosis and management of patients with stable ischemic heart disease: executive summary: a report of the American College of Cardiology Foundation/American Heart Association Task Force on Practice Guidelines, and The American College Of Physicians, American Association for Thoracic Surgery, Preventive Cardiovascular Nurses Association, Society for Cardiovascular Angiography and Interventions, and Society of Thoracic Surgeons. Circulation. 2012;126:3097-3137.

9. Borden WB, Redberg RF, Mushlin AI, Dai D, Kaltenbach LA, Spertus JA. Patterns and intensity of medical therapy in patients undergoing percutaneous coronary intervention. JAMA. 2011;305:1882-1889.

10. Ko DT, Krumholz HM, Wang Y, Foody JM, Masoudi FA, Havranek EP, You JJ, Alter DA, Stukel TA, Newman AM, Tu JV. Regional differences in process of care and outcomes for older acute myocardial infarction patients in the United States and Ontario, Canada. Circulation. 2007;115:196-203.

11. Holmes DR, Jr, Gersh BJ, Whitlow P, King SB III, Dove JT. Percutaneous coronary intervention for chronic stable angina: a reassessment. JACC Cardiovasc Interv. 2008;1:34-43.

12. Mark DB, Naylor CD, Hlatky MA, Califf RM, Topol EJ, Granger CB, Knight JD, Nelson CL, Lee KL, Clapp-Channing NE, et al Use of medical resources and quality of life after acute myocardial infarction in Canada and the United States. N Engl J Med. 1994;331:1130-1135.

13. Tu JV, Pashos CL, Naylor CD, Chen E, Normand SL, Newhouse JP, McNeil BJ. Use of cardiac procedures and outcomes in elderly patients with myocardial infarction in the United States and Canada. N Eng/J Med. 1997;336:1500-1505.

14. Ko DT, Tu JV, Austin PC, Wijeysundera HC, Samadashvili Z, Guo H, Cantor WJ, Hannan EL. Prevalence and extent of obstructive coronary artery disease among patients undergoing elective coronary catheterization in New York State and Ontario. JAMA. 2013;310:163-169. 
15. Ko DT, Tu JV, Samadashvili Z, Guo H, Alter DA, Cantor WJ, Hannan EL. Temporal trends in the use of percutaneous coronary intervention and coronary artery bypass surgery in New York State and Ontario. Circulation. 2010;121:2635-2644.

16. Shaw JC. Oh, canada: comparing single-payer health care with practice in the United States. Am J Med. 2005;118:1064-1066.

17. Tu JV, Bowen J, Chiu M, Ko DT, Austin PC, He Y, Hopkins R, Tarride JE, Blackhouse G, Lazzam C, Cohen EA, Goeree R. Effectiveness and safety of drug-eluting stents in Ontario. N Eng/ J Med. 2007;357:1393-1402.

18. Ko DT, Wijeysundera HC, Yun L, Austin PC, Cantor WJ, Tu JV. Effectiveness of preprocedural statin therapy on clinical outcomes for patients with stable coronary artery disease after percutaneous coronary interventions. Circ Cardiovasc Qual Outcomes. 2011;4:459-466.

19. Ko DT, Yun L, Wijeysundera HC, Jackevicius CA, Rao SV, Austin PC, Marquis JF, Tu JV. Incidence, predictors, and prognostic implications of hospitalization for late bleeding after percutaneous coronary intervention for patients older than 65 years. Circ Cardiovasc Interv. 2010;3:140-147.

20. Levy AR, O'Brien BJ, Sellors C, Grootendorst P, Willison D. Coding accuracy of administrative drug claims in the Ontario drug benefit database. Can J Clin Pharmacol. 2003;10:67-71.
21. Mehta RH, Roe MT, Chen AY, Lytle BL, Pollack CV, Jr, Brindis RG, Smith SC, Jr, Harrington RA, Fintel D, Fraulo ES, Califf RM, Gibler WB, Ohman EM, Peterson ED. Recent trends in the care of patients with non-ST-segment elevation acute coronary syndromes: insights from the Crusade initiative. Arch Intern Med. 2006; 166:2027-2034.

22. Steinberg BA, Steg PG, Bhatt DL, Fonarow GC, Zeymer U, Cannon CP. Comparisons of guideline-recommended therapies in patients with documented coronary artery disease having percutaneous coronary intervention versus coronary artery bypass grafting versus medical therapy only (from the Reach International Registry). Am J Cardiol. 2007;99:1212-1215.

23. Stafford RS, Radley DC. The underutilization of cardiac medications of proven benefit, 1990 to 2002. J Am Coll Cardiol. 2003;41:56-61.

24. Rothberg MB, Sivalingam SK, Ashraf J, Visintainer P, Joelson J, Kleppel R, Vallurupalli N, Schweiger MJ. Patients' and cardiologists' perceptions of the benefits of percutaneous coronary intervention for stable coronary disease. Ann Intern Med. 2010;153:307-313.

25. Lin GA, Dudley RA, Redberg RF. Cardiologists' use of percutaneous coronary interventions for stable coronary artery disease. Arch Intern Med. 2007; 167:1604-1609.

26. Nallamothu BK, Krumholz HM. Putting ad hoc PCl on pause. JAMA. 2010; 304:2059-2060. 